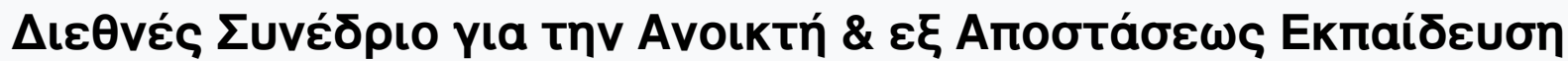

Tón. 6, Ap. 1A (2011)

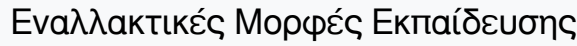

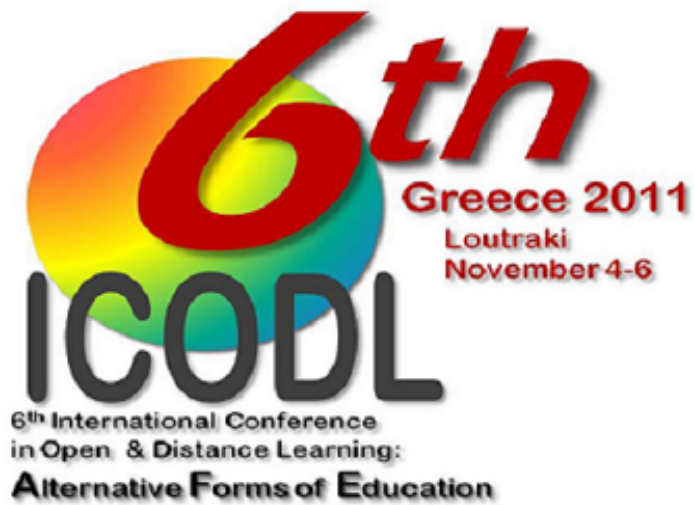

\begin{abstract}
A PARADIGMATIC SHIFT IN DEVELOPING COGNITIVE STRATEGY IN HIGHER/DISTANCE EDUCATION
\end{abstract}

\author{
Lynette Naidoo
}

doi: $10.12681 /$ icodl.694

TOMOEA

PART/ MEPOEA 


\title{
A PARADIGMATIC SHIFT IN DEVELOPING COGNITIVE STRATEGY IN HIGHER/DISTANCE EDUCATION
}

\author{
Lynette Naidoo \\ Department of Communication Science \\ University of South Africa \\ Lecturer \\ lnaidoo@unisa.ac.za
}

\begin{abstract}
ICTs in higher/distance education are becoming increasingly important due to the transactional distance that they are able to bridge. However, conventional and traditional pedagogical tools are also useful and relevant. The aim of this paper is to discuss the importance of embracing multimodal pedagogies in higher/distance education institutions' towards creating a self-directed learning environment. In order to realise the objectives, a theoretical examination of e-learning, pedagogy and heutagogy was carried out in the form of a review of the literature. Additionally, a qualitative empirical study was conducted which involved focus-group interviews with students at the University of South Africa, an ODL institution. The study used Vygotsky's zone of proximal development as the theoretical framework which refers to the space in which learning takes place. It is the educational institution, with the assistance of appropriate pedagogical tools that are responsible in facilitating the student's cognitive readiness to enter the respective field of expertise. The data collected was analysed through thematic categorisation. The study found that there is a need for distance education students to engage with lecturers or tutors in order to bridge psychological gaps which e-learning on its own is unable to achieve.
\end{abstract}

Keywords: Higher/distance education, dialogy, cognition, e-learning, pedagogy, heutagogy, constructivism

\section{Introduction}

This article aims to discuss the role and importance of embracing multimodal pedagogies in higher/distance education institutions' towards creating a self-directed learning environment. The term distance learning refers to learning that is conducted by someone removed in time and space from the students, referred to as 'transactional distance' (UNESCO, 2002:8) and the concept of pedagogy refers to the art of teaching (Whitehead, 2005). Pedagogy further describes the collected practices, processes, strategies, procedures and methods of teaching and learning. A brief overview of andragogy and heutagogy is necessary to illustrate the move to self-determined learning. Hase and Kenyon (2000) argue that pedagogy refers to learning whereby the teacher determines and directs what is to be learnt and how. In andragogy, the learning is determined by the teacher and directed by the learner; and in heutagogy, both determination and direction shift to the learner. A more in-depth explanation is provided later in the discussion.

E-learning is a process that facilitates and opens avenues for effective teaching as a result of its potential to bridge the transactional distance among all stakeholders at the 
institution thereby encouraging a self-determined learning process. E-learning refers to methods of teaching and learning that enables students in cyberspace to connect and interact, quickly and efficiently, to enter into regular discussions and dialogues and to form virtual communities (Mealy \& Loller, 2000:1). The term epistemology refers to the learning experience and it is pertinent as this paper argues in favour of the adoption of relevant pedagogical tools in higher/distance education. This would positively impact students' higher order cognition with the aim of developing students' cognition.

The significance of this paper is the contribution that it will make towards developing an integrated multimodal pedagogical model for higher/distance education. For the purposes of this paper, multimodal pedagogies refers to a blend of learning methods which include e-learning as well as traditional face-to- face teaching in a classroom.

The study used Unisa, a higher/distance education institution in South Africa which uses ODL as its mode of teaching and learning, as context. Unisa was founded in 1873 and services approximately 310000 students. It is the fifth largest mega ODL education institution in the world (Sonnekus, Louw \& Wilson, 2006) and uses the myUnisa platform as its Learning Management System (LMS) for academic collaboration and study-related interaction. myUnisa is an online platform for learning, which is used in conjunction with various other forms of learning at Unisa.

The problem that was investigated relates to the low throughput rate at higher/distance education institutions in South Africa (Human Sciences Research Council (HSRC), 2008). Consequently, there is a need for interventions and pedagogies to be developed that are unique to the higher/distance education system to enhance the learning process.

\section{Methodology}

The study used a qualitative research approach in order to encapsulate the different viewpoints of its target population by means of focus-group interviews. The population group consisting of 2828 BA: Communication Science students from Unisa, was stratified according to the nine geographic provinces in South Africa as well as their level of study. Two groups of 12 students per province (216 students in total) were selected for the focus group interviews using systematic sampling. These interviews provided the students with an opportunity to share their experiences, and an insight was gained on the flow and quality of the learning process. The data was analysed using thematic categorisation.

\section{The theoretical framework: Vygotsky's Zone of Proximal Development}

This study applied the theory of engagement as its guiding principle and used the Zone of Proximal Development (ZPD) as the theoretical framework. This theory refers to the space in which learning takes place (Hedegaard, 1996: 179; Lee, 2000: 194). Lev Vygotsky, a constructivist theorist, emphasised the role of individual interactions with their socio-cultural environment in the process of constructing knowledge and called it the zone of proximal development (Knauer \& Alexander, 2006: 2). It is the distance between the actual developmental level as determined by independent problem solving and the level of potential development as determined through problem solving under adult guidance or in collaboration with more capable peers (Lee, 2000: 191). The student learns by engaging fully in this zone, particularly through dialogue. Vygotsky believed that the outcome and objective of learning was the development of individual consciousness, experiencing self-mastery through a process of reflection as well as interaction with people and objects in the external 
world (Chaiklin, 2003: 40).

In other words, the ZPD is created in the interaction between the student and the coparticipants in an activity, including the available tools and the selected practices, and depends on the nature and quality of that interaction as much as on the upper limit of the learner's capability (Knauer \& Alexander, 2006: 2). Genuine personal engagement is the key in the dialogic learning process, according to the ZPD theory.

This theory was originally developed to argue against the use of academic, knowledge-based tests as a means to gauge students' intelligence. Vygotsky argued that, rather than examining what a student knows in order to determine intelligence, it is better to examine his or her ability to solve problems independently and his or her ability to solve problems with an adult's help (Chaiklin, 2003: 40).

Vygotsky further claimed that instruction is good only when it proceeds ahead of development (Lee, 2000: 191). Then it awakens an entire set of functions in the stage of maturing, which lie in the zone of proximal development. It is in this way that instruction plays an extremely important role in development and this study looks at multimodal pedagogical tools in advancing this development.

To fully engage and challenge the learner, the task and learning environment should reflect the complexity of the environment that the learner should be able to function in at the end of learning. Learners must not only have ownership of the learning or problem-solving process, but of the problem itself, which relates to the concept of heutagogy, defined earlier in this paper.

ZPD and the student's upper limit of cognition relates to Freire's (1970:53) argument that the truly revolutionary project, which is enabled by the process of dialogue and mediated by the outcomes of conscientisation, creates a process during which the people assume the role of subjects. Freire (1985:53) further states that the reference to subjects is synonymous with people's independence and integrity. The aforementioned concepts are relevant in this study, as higher/distance education students should be viewed as subjects of education who are active participants and not mere objects who receive information through the set curriculum.

Freire also refers to active reflection and reflective action, referred to as praxis which implies that dialogue cannot exist unless it involves critical thinking, that is, thinking which perceives reality as a process and a transformation, rather than as a static entity (Taylor, 1993:56-57). Freire criticises a 'banking' model of education where the teacher makes deposits which the students patiently receive, memorise and reproduce and serves only to increase the recipients' dependence upon the teacher and to perpetuate their oppressed conditions. Instead, Freire suggested a model in terms of which education becomes a dialogue during which both the teacher and student learn from each other (Freire, 1970:53).

Freirean dialogue is relevant in this article as it relates to the zone of proximal development because of its reference to the concepts of dialogue, reciprocation and participation in the learning process. These are elements that are necessary in higher/distance education's context in order to effect a deep and meaningful learning experience. The paper provides a discussion towards an all encompassing pedagogical framework in higher/distance education.

\section{Discussion of findings}

Below is a discussion of the themes that emerged during the empirical study and the review of the literature. 


\subsection{Multimodal pedagogies}

As distance education has evolved, so too have the roles of student, teacher and institution in the system. Distance education no longer has a distinct pedagogy common to all its forms. The pedagogy of synchronous remote-classroom teaching resembles the pedagogy of classroom teaching more than that of traditional asynchronous correspondence teaching. The development of pedagogy most suited to each mode of distance education remains a challenge (Katz, Millin \& Offir, 1996: 75). This paper refers to multimodal pedagogies as the catalyst in developing the learner's capability, and not just embedding discipline based skills and knowledge. As educators, we should relinquish any power we deem ourselves to have and emphasise a more holistic development in the learner of an independent capability. Freire (1985: 116) indicates that education should be more than adapting the learner to the lecturer's environment. Freire further states that education will be lacking if the lecturer expects that the good student is one who repeats, who renounces critical thinking and adjusts to models. On the contrary, a good student should be one who is restless or intractable, or one who reveals one's doubts or wants to know the reason behind facts, or one who breaks with pre-established models, or one who refuses to be an object. Not only does one have to select appropriate pedagogies carefully, but the divergent backgrounds of learners must be taken into account. The study shows that there will always be a need for paper resources as this is preferred by some students.

The $21^{\text {st }}$ century learner requires educational opportunities not bound by time or place, yet allow interaction with the instructor and peers. Voice and videoconferencing, live presentation tools, application sharing, chats and emails are just a few of the many tools available for interaction and collaboration. Blogs, wikis and podcasts, as well as social software are emerging technologies that foster the sense of connectedness in distance education (Beldarrain, 2006).

This paper looks at a holistic epistemological framework as the key in facilitating the learning process thereby developing students' cognition by using multimodal pedagogies.

\subsection{Critical pedagogy}

Critical pedagogy, a term coined by Paulo Freire, views education as a broad form of knowledge (Freire, 1970:74) which demands critical educators and not just subject experts in the learning process. It is important to acknowledge this autonomy and independence in education, as it relates directly to cognition building. Dheram (2007) asserts that critical educators realise the ever changing nature of the components of the educational context and it is the critical pedagogue who realises that the change is a result of the constant interaction between every component of the context, whereby engagement and action are as important to critical pedagogy as knowledge.

Critical pedagogy challenges conventional views of the relationship between student and teacher, and argues that academics are transformative intellectuals (McArthur, 2010). Whereas traditional pedagogical approaches emphasise the teacher as knowledge broker and the student as receiver of knowledge, critical pedagogy places emphasis on the student as student in a social context and knowledge as produced within a social context (Travers, 1999). But academics cannot, according to Giroux (cited in McArthur, 2010) adopt this transformative role while situated within conventions:

Locked within traditional disciplinary boundaries and recycling old orthodoxies, many critical educators risk becoming like shadows dancing on the wall of an obscure academic conference, oblivious to an outside world that is filled with real threats to democracy, society and 
education.

An evaluation of Freire's theory reveals an emphasis on the educator as the initiator of the conscientisation and dialogue process. In this paper, the initiator of the learning process is the lecturer, who Freire (1985:54-55) identifies as the person responsible for proposing problems about the codified existential situations in order to help students arrive at a more critical view of their reality. Freire argues that the educator whose approach is mere memorisation is anti-dialogical; his/her act of transmitting knowledge is inalterable. On the other hand, the act of knowing is demonstrated by the educator who experiences the education process together with his/her students through dialogue.

\subsection{Pedagogy - andragogy - heutagogy continuum}

Education has traditionally been seen as a pedagogic relationship between the teacher and the learner. It was always the teacher who decided what the learner needed to know, and indeed, how the knowledge and skills should be taught. Andragogy provides many useful approaches for improving educational methodology, but it still has connotations of a teacher-learner relationship. It is argued that the rapid rate of change in society suggests that we should now be looking at an educational approach where the learner has more autonomy in terms of what and how learning should take place. Heutagogy, the study of self-determined learning, may be viewed as a natural progression from earlier educational methodologies and may well provide the optimal approach to learning in the twenty-first century (Hase and Kenyon, 2000).

In our current digital age information is readily and easily accessible; where change is so rapid that traditional methods of training and education are totally inadequate; discipline based knowledge is inappropriate to prepare for living in modern communities and workplaces; learning is increasingly aligned with what we do; modern organisational structures require flexible learning practices; and there is a need for immediacy of learning. In response to this environment there have emerged some innovative approaches that address the deficiencies of the pedagogical and andragogical methods.

The thrust that underscores the heutagogical approach is a desire to go beyond the simple acquisition of skills and knowledge as a learning experience. They emphasise a more holistic development in the learner of an independent capability. Heutagogy or the study of self-directed/determined learning, a concept coined by Stewart Hase, may be viewed as a natural progression from pedagogy and andragogy (Lee, 2000: 191) and encourages knowledge sharing. It is learner-centred as opposed to teacher-centred learning and requires self-discipline and meta-cognitive processes (Major \& Levenburg, 2000:58). Heutagogy is discussed in this paper as it is relevant in the distance education environment. Since learners may choose when they will actively engage in the learning process, they must have the self-discipline and timemanagement skills to 'keep up' with the expected learning schedule and pace. Since employers expect similar skills, distance education should encourage this expectation and view it as an advantage in the learning process.

The second requirement, according to Major and Levenburg (2000:58) is metacognition, whereby the learners ask themselves if learning has taken place. If the answer is "no", the learner must either repeat the previously engaged-in learning activities or ask for help. This process differs from many traditional learning systems, because in distance education, it is not often possible to read non-verbal cues to detect learners who need further assistance. 


\subsection{Independent cognitive proficiency}

The danger that exists is that education as a modernist institution is characterised by the 'spaces of enclosure' which include the book, the classroom and the curriculum. These work to enclose meaning of experience through a fixed and obligatory curriculum. What emerges is a situation where the learner's task becomes one of extracting and re-presenting a singular, prescribed meaning, and the teacher is seen as the 'authority' in terms of interpretation and accuracy, with the implication that there is a single definitive meaning waiting to be found (Edwards \& Usher, 2000:48).

Edwards and Usher (2000:48) claim that developments made possible by the use of ICTs in education work in ways that call these spaces of enclosure into question - a questioning of underlying assumptions about the linear text and the teacher as authoritative bearer of meaning. This in turn opens up possibilities for rules to be more diverse and purpose-driven. Hence, the situation is created where learners do not simply interpret meanings, but actively collaborate in creating meanings, and thus take more responsibility for their own paths of learning, which aligns with the concept of heutagogy.

There is thus a shift from meaning to meaning-making, from silos of knowledge to key skills, which is aligned with Anderson's suggestions (in Big dog \& little dog's performance juxtaposition, 2009) regarding Bloom's taxonomy where creating and not evaluating, is at the apex of the learning process. In other words, the students' construction of knowledge takes place after having been equipped and enabled to engage in higher order, independent thinking proficiency thereby contributing to lifelong learning aptitude.

According to Kling (1996:17) critical thinking is a disposition, a way of approaching issues and materials. It is a readiness to consider alternative explanations, not taking key ideas for granted when it might be reasonable to doubt them. It is frequently a challenge to conventional ways of thinking and to passively accepting every text you read as comparably authoritative. Various teaching strategies should be explored that go beyond simply providing students with a body of diverse books or articles to read and analyse.

The paper argues that cognitive skills may be developed by encompassing the relevant distance education pedagogy which relates to Lawless' (1979: 337) assertion that it is important to enable the student to develop learning ability which focuses attention on cognitive strategy. It is therefore important for the lecturer to adopt appropriate pedagogical frameworks to develop relevant cognitive skills in the higher/distance education student and this paper refers to the use of multimodal pedagogies as the means towards accomplishing such development.

\subsection{Engagement}

The empirical study showed that the need for support that was required by students in order to acquire high-level cognition and reach independent and self-determined learning may be achieved through maximum engagement and dialogue with students initiated by the lecturer. This may be possible through multimodal pedagogies which provide the necessary support and scaffolding meant to facilitate the student's deep learning experience. Students indicated that additional tutors should be employed at the regions because it is the physical contact that students needed. One of the students responded as follows: "We do not like it when our lecturers refer us to the study guide or tutorial letter when in fact we call for personal assistance and conversation with our lecturer. We need guidance and time from our lecturers when we phone". 


\subsubsection{Discussion classes}

The empirical study indicated that a discussion class is a preferred way of learning because of its personal and dynamic nature. Feedback and discussions are immediate and vibrant during these forums. However, a student indicated the following: "We prefer to have discussion classes and meet our lecturers personally, but tutorial classes or satellite broadcasts can be used to replace them, considering that discussion classes are only held at selected regions".

\subsubsection{Tutorial classes}

In a conventional system of education, learning is greatly influenced by the dynamic interaction process that occurs between a teacher and his/her students. In distance education such face to face interaction is infrequent; therefore tutors are considered a necessary component towards developing cognition and the achievement of education goals and objectives.

During the empirical study, students indicated that they are in favour of scheduled tutorial classes at the various regions. These classes accommodate students in all the provinces, but the challenge that emerged was that not all modules have tutorial classes, and this contradicted Unisa's undertaking that regional offices will provide necessary academic support. It was suggested that an audit be carried out to ascertain which modules do provide tutorial classes.

\subsubsection{Satellite broadcasts}

During the empirical study, students responded positively to the use of satellite broadcasts for their studies, indicating that it is an effective method of tuition. A student indicated the following: "It is a good platform where I am able to 'meet' my lecturers". Students also indicated that real-life situations to immerse the student should be provided in order for authentic learning to occur and this relates to Vygotsky's Zone of Proximal Development. Students have indicated that they need to engage with their lecturer during these broadcasts, which ties in with the concept of heutagogy, which was defined and discussed earlier in this paper. A student said: "Lecturers should provide more content specific information during the broadcast and not primarily general information about the module", which points to the fact that students want to engage with lecturers during the learning process.

\subsubsection{Video-conferences}

It is important to note that technology as a tool cannot teach anything; hence it is the human element that is viewed as an essential component in the education process. Therefore, the key is to create a set of tools that can be used more effectively to leverage the lecturer's time and energy to aid the learning process. During the interviews, students indicated that video conferences are beneficial in their studies. Video conferences create a personal atmosphere that allows interaction and authentic engagement with the lecturer. A student indicated the following: "Video conferences allows for better communication to occur. It is free flowing and we can communicate with our lecturer as though he/she is in the same room".

\subsection{5 myUnisa}

myUnisa has been developed to supplement and enhance academic interaction and improve communication between Unisa and its students, as well as provide an opportunity for engagement among students. At Unisa, the learning process involves 
being part of a learning community where students can engage with their peers. In a typical distance learning environment, this opportunity for engagement is limited; therefore, myUnisa was launched with the intention of helping to bridge this gap.

The findings show that the issue of computer skills and access to computers and the internet is of primary concern to students. On the one hand it reinforces and enhances ideas of ODL whereby distance is bridged in the learning process, yet at the same time it creates a problem of access and computer competency challenges on the other. Subsequently, e-learning inherently poses the threat of a digital divide and societal inequality if not addressed by the education institution.

\subsection{En route to learner autonomy}

Stahl (2000:111) states that most educators agree, that students place more belief in knowledge they have discovered on their own than in knowledge presented by others; yet these teachers fail to trust students to learn anything that is not explicitly stated by the teacher. Stahl (2000:112) further asserts that educators often adopt a behaviourist rather than a constructivist approach in their instructional design because the educator often becomes so focused on the desired outcome that the process by which the outcome can best be attained is forgotten or ignored. If this is the case in distance education, whereby the information diffusion model (Rogers, c1983:125) is used, then the educator is failing to support the very learning that leads to the development of higher level cognitive skills and long-term change.

In $21^{\text {st }}$ century education, focus should be on managing knowledge, and not on information diffusion, because adding and preserving knowledge is a key component in education and using multiple modes of engagement can assist in distance education. Constructivism is a crucial component of technology integration. It is a learning theory that describes the process of students constructing their own knowledge through collaboration and inquiry-based learning. According to this theory, students learn more deeply and retain information longer when they have a say in what and how they will learn (Stahl, 2000: 112).

Stahl (2000:113) proposes that a cohesive approach to education be utilised to support changes in cognition, affect and behaviour, which relates to Bloom's taxonomy (SAQA, 2008). In a distance education mode, this cohesion requires instructional designers to plan cognitively challenging tasks, address the affective issues that stimulate student recognition of the need for change, and provide opportunities for action. Moreover, motivational aspects should also be included in instruction.

However, in order to achieve the aforementioned cognitive abilities in students, it is essential to create a conducive learning environment in the distance mode - a community of students. This dialogical relationship is a sign of the cognitive act in which the knowing object, mediating the knowable subjects, gives itself over to a critical revelation (Freire, 1985:167). The significance of seeing this dialogical relationship becomes clear whenever we take an epistemological cycle as a totality, rather than splitting it into one stage for acquiring existing knowledge and another stage for discovery or the creation of new knowledge, which echoes Freire's (1985:167) concept of conscientisation.

According to Srampickal (2006) conscientisation comprises several stages, starting with 'intransitive thought' during which people believe that control over their lives is out of their hands and that fate defines their experience. In order words, they do not perceive that their own actions are capable of changing their conditions. 'Semitransitive thought' is the next stage towards conscientisation, where people believe partially in themselves as motors of change and, to some degree, they try to act in 
order to bring about social change (Srampickal, 2006). However, at this stage, people's understanding of their situation is still fragmentary insofar as they fail to connect their particular problems to the larger societal determinants which underlie single situations. The final stage, which Freire (1970:71) terms 'critical transitivity', corresponds to the achievement of conscientisation. This stage involves a dynamic relationship between critical thought and critical actions which is triggered by the ability to think holistically and critically about one's condition.

A preliminary step in achieving conscientisation is establishing a social environment though synchronous and/or asynchronous means through video conferencing, satellite broadcasting, podcasts and discussion forums. Students' questioning of viewpoints and theories and critical analysis and debate can support rich learning experiences and group sharing that supports individual responsibility and distributed learning, and this should be encouraged by the lecturer. If active learning is seen as the primary mode of instruction and not as a supplement to the lecture, such learning will lead to permanent high level cognitive development. This relates to Kearsley's and Shneiderman's (1999) engagement theory which emphasises engaged learning that involves active cognitive processes such as creating, problem-solving, reasoning, decision-making and evaluation. In addition, students are intrinsically motivated to learn due to the meaningful nature of the learning environment and activities that such engagement induces in a distance education mode of learning.

A review of the literature shows that e-learning is positively impacting higher/distance education. However, the opportunities and limitations of each technology-supported delivery should be critically analysed so that higher/distance educators may teach using appropriate pedagogical techniques in order for students to gain through innovative solutions to the myriad delivery issues that educators are faced with.

\subsection{Technology as enabler in higher/distance education}

The use of technology in higher/distance education has innumerable advantages as has been discussed thus far in this article. However, Chickering and Ehrmann (1996) state that technology should fulfil the following criteria, regardless of the delivery method:

- Encourage contact between students and the university

- Develop reciprocity and cooperation among students

- Use active learning techniques

- Give prompt feedback

- Emphasise time on task

- Communicate high expectations

- Respect diverse talents and ways of learning

The seven principles along with the specific needs of the qualification will help determine the purpose and rationale of integrating the particular technology, and how it benefits the learner. According to Maor (2006), if the use and understanding of technology in teaching is seen as a separate issue to that of teaching in itself, the gap between pedagogy and technology will increase. In other words, if the primary focus of the lecturer is on pedagogy, and technology is just seen as another mode of delivery designed to enhance the teaching and learning experience, then technology and pedagogy will be seen as existing separately, with one having minimal impact on the other. However, if elements of technology and pedagogy are considered as mutually supportive and interdependent, then it would be possible to construct new meaning about teaching in higher/distance education. 


\section{Conclusions}

This paper based its argument on the assumption that the value of multimodal methods of teaching is in its capacity to facilitate communication, thinking, and to construct meaning and build knowledge, a process that will be mutually beneficial to both the educator and the student.

A review of the literature on higher/distance education and pedagogical frameworks as well as the focus group interviews shows that conventional learning should be integrated with technology in higher/distance education in order to accelerate student performance; learning should be linked with knowledge construction to optimise performance and finally, learning strategy should be appropriate to the university's local needs and resources.

It is difficult for educators to develop a cohesive, long-term learning strategy if one begins with the technology, because technology changes rapidly. It is recommended that a learning strategy be built into the outcomes to incorporate student-centredness and engaged learning which relates to the underpinning theory of this article, namely the zone of proximal development. In addition, Freire (1970:73) argues in favour of participatory, dialogic and reciprocal communication, and this may be possible through the introduction of relevant and appropriate pedagogies in higher/distance education.

The paper proposes the development of an epistemological framework which is integrative, rather than delimiting in orientation; incorporating current as well as future trends and realities, rather than merely the present; process driven; and consistent with the current and future state of society and education with a strong theoretical underpinning. Beldarrain (2006) argues that the lecturer's role should be that of partner in learning, one that probes and challenges students to become reflective, critical thinkers. Edwards and Usher (2000:49) concur with Beldarrain (2006) by asserting that a shift of emphasis from a pedagogy of transmission to the pedagogue as creator of a learning environment should take place.

The framework that this study proposes is considered to enable the promotion of new ways of learning that are reciprocal between students and peers, and students and the lecturer. Depending on the nature of content, scope of content and level of students, appropriate technology integration together with appropriate contact with students must be sought. This paper concludes that multimodal methods of teaching enhances the process of learning and helps in achieving higher level cognitive objectives. In addition, it is both conventional and e-learning teaching methods that enable the process of critical transitivity, a requirement for learners to engage in knowledge construction in order for meaningful learning to take place, which is also aligned with Vygotsky's zone of proximal development theory.

The study concludes that students' reflective judgement could be developed by meeting them at their current level of development with experiences which challenge those epistemological assumptions and support activities that operate at a higher stage through introducing multimodal pedagogies. This development allows students to reach higher cognitive levels through a heutagogical epistemology.

It is recommended that further empirical research studies be conducted by distance education universities to determine the barriers that impede meaningful engagement and further research to determine the extent of knowledge-building components that are built into existing curricula. The paper concludes that the learning process is a form of re-inventing, re-creating and re-writing and as educators in the higher/distance education process, we should immerse ourselves in the learning process with our students, which reverberates Freirean dialogue (Freire: 1970:53). 
Technology should not be viewed as the transforming agent, but rather it is the lecturer who will transform the learning environment in a pedagogically responsible and appropriate manner with the assistance of appropriate learning methods.

Creating an enabling and effective educational environment assumes the use of different instructional strategies and learning approaches based on constructivism, which will extend learners' cognitive capabilities. Using multimodal pedagogical tools could extend learners' conceptual knowledge. A shift in teaching from low-level to complex thinking may be achieved by using the tools that were discussed in this paper. Education is the heart of rich content, expertise and knowledge exchange. With the use of multimodal pedagogies, such knowledge exchanges and deep learning becomes possible in an ODL context.

Finally, the article has shown that heutagogy, the process of self-directed learning, is helping reinvent the very fundamentals of the learning process - from instructional design, to evaluation of results, to who controls the learning experience, which will eventually result in a holistic epistemological experience for all in the learning community.

As lecturers in higher/distance education, we constantly challenge our students' ways of thinking. Similarly, we must be open to be challenged ourselves by thinking about, and attempting new approaches to teaching.

Finally...

It is impossible to study seriously if the student is expected to read a text as though magnetised by the author's word, mesmerised by a magical force; if the reader behaves passively trying only to memorise the author's ideas; if the reader allows him/herself to be "invaded" by what the author affirms; if the reader is transformed into a "vessel" filled by extracts from an internalised text" (Freire, 1985: 2).

\section{References}

Beldarrain, Y. (2006). Distance education trends: integrating new technologies to foster student interaction and collaboration, Retrieved on 10 March 2010 from http://pdfserve.informaworld.com/446370_731328375_749174134.pdf

Big dog \& little dog's performance juxtaposition. (2009). Blooms' taxonomy of learning domains: the three types of learning, Retrieved on 13 May 2010 from http://www.nwlink.com/ donclark/hrd/bloom.html

Chaiklin, S. (2003). The zone of proximal development in Vygotsky's analysis of learning and instruction, in Kozulin, A, Gindis, B, Ageyev, V. and Miller, S.M., Cambridge University press, Cambridge

Chickering, A.W. and Ehrmann, S.C. (1996). Implementing the seven principles: technology as lever, Retrieved on 01 June 2010 from http://www.tltgroup.org/programs/seven.html

Dheram, P. (2007) Empowerment through critical pedagogy, Retrieved on 01 April, 2010 from http://www.academicleadership.or/empirical_research/Empowerment_through_Critical_Pedag ogy.shtml

Edwards, L. and Usher. R. (2000) Globalisation and pedagogy: space, place and identity. New York, Routledge

Freire, P. (1970) Pedagogy of the oppressed, Harmondsworth, Penguin

Freire, P. (1985) The Politics of Education, London, MacMillan

Hase, S. \& Kenyon, C. (2001). From Andragogy to Heutagogy. Retrieved on 11 June, 2010 from http://ultibase.rmit.edu.au/Articles/dec00/hase2.htm

Hedegaard, M. (1996). The zone of proximal development as basis for instruction, in An introduction to Vygotsky, Editor: Daniels, H. Routledge, London

Human Sciences Research Council (HSRC). (2008). High university drop-out rates: a threat to South Africa's future. Retrieved on 10 April, 2010 from http://www.hsrc.ac.za/Document2717.phtml

Kearsley, G. and Shneiderman, B. (1999). Engagement theory: a framework for technology-based teaching and learning. Retrieved on 01 April, 2010 from http://home.sprynet.com/ gkearsley/engage.htm 
Kling, R. (1996) 'Content and pedagogy in teaching about the social aspects of computerisation' in The impact of information technology: from practice to curriculum, Editors: Katz, Y.J., Millin, D. and Offir, B. London, Chapman and Hall

Knauer, J.T. and Alexander, P. (2006). Dialogue as pedagogy: deliberate learning with democracy lab in high school and college classes. Proceedings of the National Coalition for dialogue and deliberation. San Fransisco, California. October 4-6, 2006

Lawless, C.J. (1979). Information processing: a model for educational technology, in Educational technology twenty years on, Editors: Page, G.T. and Whitlock, Q.A. New York, Nichols Publishing Company

Lee, C.D. (2000). Signifying in the zone of proximal development, in Vygotskian perspectives on literacy research, Editors: Lee, C.D and Smagorinsky, P. Cambridge, Cambridge University Press

Maor, D. (2006). Pushing beyond the comfort zone: bridging the gap between technology and $\begin{array}{llllll}\text { pedagogy. } & \text { Retrieved } & 01 & \text { April, } & 2010 & \text { from }\end{array}$ http://www.ascilite.org.au/conferences/perth04/procs/pdf/maor.pdf

McArthur, J. (2010). Time to look anew: critical pedagogy and disciplines within higher education.

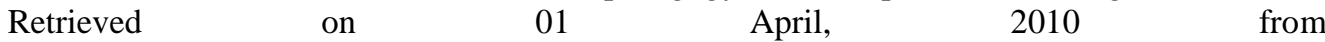
http://pdfserve.informaworld.com/24377_751308860_918636287.pdf

Rogers, E.M. (c1983). Diffusion of innovations, $3^{\text {rd }}$ edition, New York, Free Press

SAQA (South African Qualifications Authority). (2008). Bloom's taxonomy. Retrieved on 01 March, 2010 from http://www.nqf.org.za/download_files/nqfsupport/13\%20Bloom's\%20Taxonomy.pdf

Stahl, S. (2000). Brining old ideas to new times: learning principles of Kurt Lewin applied to distance education, in E-learning: expanding the training classroom through technology, Editors: Mealy, L. and Loller, B. Chicago, Rector Duncan and Associates

Sonnekus, P., Louw, W. and Wilson, H. (2006). Emergent learner support at Unisa: an informal report. In Progressio, 28 (1), Retrieved on 12 March, 2010 from http://www.unisa.ac.za/contents/faculties/service_dept/bld/progressio/docs/Emegent\%20LS.p df

Taylor, P. (1993). The texts of Paulo Freire, London, Open University Press

Travers, A. (1999). New technology and critical pedagogy. Retrieved on 01 April, 2010 from http://radicalpedagogy.icaap.org/content/issue1_2/01travers1_2.html

UNESCO. (2002). Open and distance learning: trends, policy and strategy considerations. Retrieved on 12 March, 2010 from http://unesdoc.unesco.org/images/0012/0012/001284/128463e.pdf

Whitehead, B. (2005). The pedagogy behind distance education and making it a rewarding experience. Retrieved on 10 March, 2010 from http://www.web-conferencing-zone.com/4086pedagogy.htm 